\title{
The Effects of Experience on Preferences: Theory and Empirics for Environmental Public Goods
}

\author{
Mikołaj Czajkowski
}

Nick Hanley

Jacob LaRiviere

Abstract: This paper develops a choice model for environmental public goods which allows for consumers to learn about their preferences through consumption experiences. We develop a theoretical model of Bayesian updating, perform comparative statics over the model, and show how the theoretical model can be consistently incorporated into a reduced form econometric model. Our main findings are that in a Random Utility Model (RUM) discrete choice model, a subject's scale should increase and the variability of scale should decrease with experience if subjects are Bayesians. We then estimate the model using field data regarding preferences for one particular public good, water quality. We find strong evidence that additional experience increases scale, thereby makes consumer preferences more predictable from the econometrician's perspective. We find supportive but less convincing evidence that experience decreases the variability of scale across subjects.

Keywords: Bayesian updating, choice experiment, learning, scale, scale variance

JEL Codes: C51, D83, Q51, H43

Mikołaj Czajkowski, Assistant Professor, Department of Economic Sciences, University of Warsaw, Poland, miq@wne.uw.edu.pl; Nick Hanley, Professor, Economics Division, University of Stirling, n.d.hanley@stir.ac.uk; Jacob LaRiviere (corresponding author), Assistant Professor, Department of Economics and Baker Center for Public Policy, University of Tennessee, jlarivi1@utk.edu. We thank the Northern Ireland Environment Agency for funding data collection for the water quality study. Dugald Tinch designed and managed the choice experiment survey used here as a source of data. We also thank MASTS (www.masts.ac.uk) for funding part of this work. Finally, we thank three referees for their very helpful comments on the original version of this paper. 


\section{Introduction}

Consumers often make decisions under uncertainty about their preferences, such as when a firm introduces a new product. Experience goods are goods for which consumers are uncertain about their preferences and learn about them with each consumption event (Nelson, 1970; 1974; Stigler et al., 1977). Economists often model experience goods by assuming consumers have a true preference parameter, or type, which they learn about through Bayesian updating. For private goods, preference uncertainty for an experience good is revealed in agents' purchasing decisions over time. However, for public goods or quasi-public goods, rich panel data to test and control for the relationship between experience and preference uncertainty or learning often do not exist because markets for public and quasi-public goods are often incomplete (Carson et al., 2014).

In the environmental economics literature, experience with a public good has been shown to matter both for measures of the predictability of consumers' preferences and as a determinant of willingness to pay (WTP) for public goods (Boyle et al., 1993; Adamowicz, 1994; Whitehead et al., 1995; Cameron et al., 1997; Breffle et al., 2000; Ferrini et al., 2007; Hanley et al., 2009). ${ }^{1}$ However, there is no broadly accepted way to test for and control for the effects and presence of experience and learning on WTP. ${ }^{2}$ This is particularly important for non-market valuation methods such as contingent valuation and discrete choice experiments (DCE) both because the public good being valued may be unfamiliar to many respondents, and because respondents are presented with information describing the public good at the beginning of the study (Bateman et al., 2004; Carson et al., 2011).

This paper develops a theoretically consistent and readily implementable method of explicitly controlling for the effect of experience on preference and willingness to pay estimates for public goods. ${ }^{3}$ Motivated by previous work in the literature, we use a simple Bayesian theoretical model to identify how additional experience would affects a consumer's preference uncertainty for an experience good 
from a Bayesian perspective (Ackerberg, 2003). We then link the theoretical model to a reduced form generalized mixed logit model (G-MNL) widely used in discrete choice experiments to estimate demand for public good and quasi-public goods. The extended G-MNL model both tests and controls for the effects of previous experience with the public good in estimating willingness to pay. It allows preferences to become more deterministic both within and across subjects from the perspective of the analyst as experience with the good increases. ${ }^{4}$ We then estimate the reduced form econometric model using a data set well-suited to test for the effects of experience on preference uncertainty.

The Bayesian theoretical model leads to two testable hypotheses when applied to the reduced form econometric model. First, in the Bayesian exercise, a consumer becomes less uncertain about their own preferences for a public good (e.g., their type) as they have more consumption experiences (e.g., more signals). Our econometric model controls for the effect of experience on preference uncertainty by allowing the model's scale parameter to be a function of experience. The scale parameter weights the importance of the deterministic portion of a random utility model (RUM) relative to the idiosyncratic portion. An increase in the scale parameter increases the relative importance of the deterministic portion of the utility function. Put another way, utility over a good, a public good becomes more deterministic from the econometrician's perspective as the scale parameter increases. Second, in the Bayesian exercise we also find that increases in experience also decrease the variance of the scale parameter across individuals. Any heterogeneity allowed in the idiosyncratic portion of a RUM is predicted to be reduced by the Bayesian model.

With respect to the first hypothesis, we find that experience, consistent with the theoretical exercise, significantly increases the scale parameter. This result is strong and robust. We find mixed evidence for the second hypothesis: experience does decrease the variance of the scale parameter but that result is only marginally significant. Significance of the result was sensitive to whether 1) we allowed for 
preference heterogeneity in the public good's price and 2) the functional form of the distribution of scale parameters. This is possibly due to lack or power in our data, as we discuss below, and merits additional research.

There are several reasons why this paper is an important contribution. First, our model offers a theoretically consistent and parsimonious empirical technique for taking experience into account for researchers using random utility-based valuation approaches. While other researchers have accounted for experience in stated preference demand estimation, we are not aware of any commonly used approach which is theoretically motivated. Second, while there is strong evidence for one of the hypotheses derived from the Bayesian model, the evidence for the second hypothesis is less robust. As a result, this paper shows a need to both better understand how experience affects preferences for public goods and develop a theoretically consistent model which captures these effects. Given that previous research shows prior experience is correlated with preferences and WTP, understanding this link is vital for forming efficient economic policy. ${ }^{5}$ Lastly, the empirical model proposed is widely implementable for both private and public good settings, and for both revealed and stated preference data. While there are other simulation based structural models that can allow control for experience explicitly (Crawford et al., 2005; Osborne, 2011), the model here is easily applicable to a widely used method for estimating demand for public and quasi-public goods. As a result, we present a parsimonious way of controlling for the effect of experience on preference uncertainty insofar as consumers are Bayesian updaters. It can be applied as a simple extension of the standard econometric approach to choice experiment data, and which is an intuitively plausible and attractive way of thinking about how people's preferences are influenced by consumption experience.

\section{Theoretical Motivation}


Using a simple Bayesian framework, this section shows the expected effects of experience on the observed choices of consumers when additional consumption events help to refine preferences for a good. We demonstrate how this framework can be carried over to the case of public goods within the

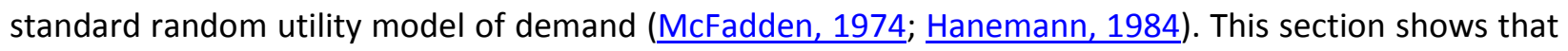
previous experience will increase the scale and decrease the scale variance heterogeneity for individual consumers.

In line with the random utility model in the experience good literature (Ackerberg, 2003), assume the utility derived from a good is:

$$
U_{i j t}=\boldsymbol{\beta}_{j}^{\prime} \boldsymbol{X}_{j}+\delta_{i j}^{t+1}+\epsilon_{i j t}
$$

where $i$ indexes an individual, $j$ a good, and $t$ time. This specification takes a Lancasterian view of utility in that individual traits of a good affect a consumer's preference for it (Lancaster, 1966). The traits or attributes of good $j$ are given by the vector $\mathbf{X}_{j}$ and marginal utility over those traits of good $j$ are $\boldsymbol{\beta}_{j}$; for exposition here, they are not assumed to be individual-specific as with a random coefficients model but could be represented in that way with no loss. ${ }^{6}$ Utility for the good is also a function of an idiosyncratic component, $\epsilon_{i j t}$, which varies with each consumption experience. This term reflects the varying levels of utility a consumer enjoys from a good. For example, it could reflect utility received from visiting a beach depending on the weather on a particular day. Importantly, this idiosyncratic component of utility is observed by the consumer before they decide to actually consume the good. The idiosyncratic utility component is assumed normal and is drawn from the same distribution for all agents in the economy: $\epsilon_{i j t} \sim N\left(0, \sigma_{\epsilon}^{2}\right)$.

There is also a component of the utility function, $\delta_{i j}^{t+1}$, which we follow Ackerberg (2003) in calling "experience utility". It is a scalar representing how much utility a consumer receives due to factors 
unobservable to them at the time of consumption (e.g., their type). This term could represent intrinsic feelings about a good (e.g., walking along a particular beach) conditional on observable characteristics. Importantly, consumers do not observe $\delta_{i j}^{t+1}$ before they consume the good; hence the $t+1$ timing of this component of utility whereas all other goods have the $t$ subscript. In the simplest case, $\delta_{i j}^{t+1}$ would be time invariant in which case consumers learn their type with certainty after one consumption experience. More generally, we model "experience utility" as the sum of a time invariant mean and random idiosyncratic component: $\delta_{i j}^{t+1}=\delta_{i j}+u_{i j t}$. The time invariant component of experience utility we call a consumer's type: $\delta_{i j}$. We assume that the idiosyncratic component is normally distributed around zero: $u_{i j t} \sim N\left(0, \sigma_{u}^{2}\right)$. Lastly, we assume that there is a known distribution of time invariant mean types across the population: $\delta_{i j} \sim N\left(0, \sigma_{\delta}^{2}\right)$.

Following Ackerberg (2003), the consumers' problem can be thought of as learning about the "true" type from a sequence of noisy signals. ${ }^{7}$ We model the learning process as a Bayesian updating procedure. Individuals never receive a signal that perfectly reveals their type in this model. Instead, individuals observe the sum of their time-invariant type and idiosyncratic random utility component (e.g., $\delta_{i j}^{t+1}=\delta_{i j}+u_{i j t}$ ). As a result, individuals must infer what their time invariant type is, $\delta_{i j}$, by evaluating the likelihood they had the experience they did given their priors over type and the distribution of the idiosyncratic error term, $u_{i j t} \cdot{ }^{8}$

Following DeGroot (1970) and Ackerberg (2003), we assume priors over a consumer's type, $\delta_{i j}$, are distributed normally, $\delta_{i j}^{o} \sim N\left(0, \sigma_{o}^{2}\right)$. After $K$ consumption experiences with the good, posterior beliefs about type can be represented as: 
Experience and Preferences for Public Goods

$$
\delta_{i j}^{K} \sim N\left(\frac{\sum_{t=1}^{K} \delta_{i j}^{t+1}}{\frac{\sigma_{\delta}^{2}+\sigma_{u}^{2}}{\sigma_{o}^{2}}+K}, \frac{\sigma_{\delta}^{2}+\sigma_{u}^{2}}{\frac{\sigma_{\delta}^{2}+\sigma_{u}^{2}}{\sigma_{o}^{2}}+K}\right)
$$

By inspection, additional experience has an ambiguous effect on the mean of beliefs over type; the relative strength of an individual's experience must be compared to the reduction in mean from additional experiences. The variance of beliefs over type is falling in experience (e.g., the second term falls as $K$ increases).

Now consider how this model of learning would manifest itself in the dynamics of consumption decisions. For exposition, assume an individual's true type is half of one standard deviation below the mean type: $\delta_{i j}=-.5 \sigma_{\delta}$, and that the variance of both the prior and true type is one. In this example, we plot the posterior distribution given an expected draw (e.g., the posterior conditional on draws of the individual i's true type: $\left.\delta_{i j}^{t+1}=\delta_{i j}+u_{i j t}=-.5\right)$ in Figure 1. Put another way, we parameterize this example so that there is no noise introduced by the idiosyncratic term. Therefore, Figure 1 shows the updating of the posterior distribution of beliefs over type, $\delta_{i j}^{K+1}$, for one and two draws respectively.

There are two important features of Figure 1. The first is that, as expected, the consumer's posterior mean type, $E\left[\delta_{i j}^{K+1}\right]$, falls given new consumption experiences because each signal is below the mean of their prior. Second, the variance around the posterior mean is decreasing as successive signals mechanically decrease the variance of posterior beliefs. In this simple example, we assume that both consumption signals are the mean true signal for expositional purposes, but this assumption can be relaxed without qualitative loss. ${ }^{9}$

Figure 1 and equation 2 above show that a model of Bayesian learning dictates that additional consumption experiences with a good will decrease the variance of a consumer's utility for that good. 
Put another way, the variance of the composite idiosyncratic term, $\delta_{i j}^{t+1}+\epsilon_{i j t}$, decreases as experience levels with a good increase. Effectively, the magnitude of the composite idiosyncratic component of utility decreases relative to the deterministic component as experience with the good increases and a consumer's uncertainty over her type is reduced. Therefore, relative to the magnitude of the deterministic component of utility (e.g., $\boldsymbol{\beta}_{j}^{\prime} \mathbf{X}_{j}$ ), the model predicts the variance of the idiosyncratic portion of an agent's utility should be falling in the amount of experience with the good as an individual has more experience with a good.

The above Bayesian model has implications not only for the magnitude of the deterministic component of utility relative to the idiosyncratic component of utility within a respondent but also for the variance of that magnitude between respondents. The variance of the full idiosyncratic portion of utility (to the econometrician) conditional on $K$ consumption events is:

$$
\operatorname{var}\left(\delta_{i j}+u_{i j t}+\epsilon_{i j t} \mid K\right)=\frac{\sigma_{\delta}^{2}+\sigma_{u}^{2}}{\frac{\sigma_{\delta}^{2}+\sigma_{u}^{2}}{\sigma_{o}^{2}}+K}+\sigma_{u}^{2}+\sigma_{\epsilon}^{2}
$$

By inspection, the variance of the uncertain portion of utility is also decreasing with experience. ${ }^{10}$

Across all agents, then, the model predicts that the variance of the idiosyncratic portion of utility should be decreasing in experience. This would be true even if different agents had 1) biased versus unbiased priors or 2 ) the strength of priors was allows to vary across the population (e.g., $\sigma_{u}^{2}$ varies by individual). Put another way, any type of heterogeneity in the variance of the idiosyncratic portion of utility would be ameliorated with additional experience.

In sum, allowing for Bayesian learning through experience creates variation in the magnitude of the deterministic component of utility relative to the stochastic component of utility. The magnitude of the deterministic component of utility relative to the stochastic component of utility is often referred to as 
the 'scale' parameter in empirical work. The theoretical model above shows that scale should increase as experience increases (e.g., the relative magnitude of the deterministic component of utility increases). Further, scale heterogeneity should decrease in experience as experience reduces the variance of the composite error term. From a theoretical perspective, not allowing the scale and scale variance to vary with experience amounts to misspecification of the error structure.

\subsection{Application to the Random Utility Model Framework.}

Consider the implications of Bayesian updating model for a multiple-good or multiple-attribute discrete choice model in a random utility framework (McFadden, 1974). The key aspect of the model presented to the econometrician is that both the consumer's idiosyncratic component of utility, $\epsilon_{i j t}$, and the experience component of utility, $\delta_{i j}^{t+1}$, are unobserved. Intuitively, then, from the econometrician's perspective the random component of utility is the sum $\varepsilon_{i j t}=\delta_{i j}^{t+1}+\epsilon_{i j t}$. As shown above, if the variance of the experience component of utility $\left(\delta_{i j}^{t+1}\right)$ decreases with experience, so must the variance of $\varepsilon_{i j t}$. This subsection presents how this artifact of the theoretical exercise above can be applied to a random utility model to consistently control for the effects of experience in a choice experiment.

Since the econometrician does not separately identify the experience and idiosyncratic portions of utility, for the remainder of the paper we combine these two components into their sum. Specifically, for the remainder of the paper the random component of utility refers to the random component of utility from the econometrician's perspective. As shown above, then, $\varepsilon_{i j t}$ refers to the sum of the experience and idiosyncratic component of utility since they are both unobserved from the econometrician's perspective. ${ }^{11}$ 
The utility associated with any choice experiment alternative can be divided into a sum of contributions that can be observed by a researcher, and a component that cannot, and hence is assumed random. Specifically consider the following empirical specification of a random parameters multinomial choice model:

$$
U_{i t}(\text { Alternative }=j)=U_{i j t}=\sigma_{i} \boldsymbol{\beta}_{i}^{\prime} \mathbf{x}_{i j t}+\varepsilon_{i j t}
$$

where:

- $\quad U_{i j t}$ represents respondent $i$ 's utility associated with selecting alternative $j$ out of a set of $J$ available alternatives at time occasion $t$;

- the stochastic component of the utility function $(\varepsilon)$ may be interpreted as resulting from researcher's inability to observe all attributes of choice and all significant characteristics of respondents (McFadden, 1976), or as decision maker's choice from a set of his decision rules (Manski, 1977).

- $\quad \mathbf{x}_{i j t}$ is a vector of respondent- and alternative-specific choice attributes, i.e. goods or their characteristics;

- $\boldsymbol{\beta}_{i}$ represents a vector of individual-specific taste parameters associated with marginal utilities of the choice attributes. The multivariate distribution of these parameters in the sample is $f$, $\boldsymbol{\beta}_{\boldsymbol{j}} \sim \boldsymbol{f}(\mathbf{b}, \boldsymbol{\Sigma})$, where $\mathbf{b}$ is a vector of sample means and $\boldsymbol{\Sigma}$ is a variance-covariance matrix, with a vector of square roots of diagonal elements $\mathbf{s}$ which represent standard deviations of random taste parameters;

- $\sigma_{i}$ is the scale parameter which normalizes the variance of $\varepsilon$ to $1 .{ }^{12}$ The scale parameter can be individual-specific, as it is reasonable to allow different agents to have relatively larger or smaller idiosyncratic components as opposed to deterministic components of the utility 
function. ${ }^{13}$ The scale heterogeneity of the agents can be described with a parameter $\tau$, such that given the scale distribution $\mathrm{g}, \sigma_{j} \sim g(1, \tau) .{ }^{14}$

The above specification of the random utility model accounts for unobserved preference heterogeneity in terms of both taste parameters and scale. In addition, one can introduce observed preference heterogeneity in the model by including individual-specific covariates of means of random taste parameters $\mathbf{b}$, their variances, the scale parameter $\sigma$ or its variance $\tau$. A convenient reduced form way of accounting for previous experience is by estimating the term $\sigma$ explicitly as a function of prior experience, $\mathbf{z}$, so that $\sigma_{j} \sim g\left(1+\boldsymbol{\Phi}^{\prime} \mathbf{z}, \tau\right)$. Allowing the vector $\mathbf{z}$ to be comprised of experience related covariates, then, operationalizes the theoretical model presented above. Specifically, the theoretical model predicts that experience related covariates should increase the mean of the scale parameter, thereby decreasing the magnitude of the error term in equation (4).

There are three important features of this characterization of the econometric model. First, there is no distinct modeling of the experience component of utility. The goal of this paper is to consistently model the effects of experience on utility in a reduced form econometric model. Actually identifying the parameters of experience utility, then, we leave to future work. Second, an agent might never receive a sufficient number of signals to discover their "true" type. For example, one sufficiently bad draw could lead to a consumer to form posteriors well below their mean experience utility - the first oyster I eat is bad and therefore I never eat another oyster even though on average I am an oyster lover. Third, we treat $\mathbf{z}$ as a count variable in the econometric model of Section 3 therefore neglecting the variability in signal strength across occasions. Put another way, using a count variable such as number of consumption experiences neglects possibly heterogeneity in the intensity of each experience. ${ }^{15}$

Allowing experience related covariates to affect the mean of the scale parameter is equivalent to allowing experience to influence all the taste parameters. ${ }^{16}$ Provided that all utility function taste 
parameters are random and they are allowed to be correlated, this effect may already be to some extent accounted for by off-diagonal elements of $\boldsymbol{\Sigma}$ (Hess et al., 2012). Collecting the common effect for all taste parameters has, however, a very interesting behavioral interpretation - allowing scale to be a function of previous experience permits the magnitude of the error term, to be systematically related to experience. As a result, the relative importance of observable characteristics in determining utility is exactly what is implied by Figure 1 above: as experience increases, agents learn their type with more certainty so that choices become less random. ${ }^{17}$

Finally, just as experience-related covariates in the mean scale collect common effects for all taste parameters, introducing experience-related covariates in the variance of the scale parameter collects common effects for variances of all random parameters. In this case, the scale variance can be modeled as a function of experience, $\sigma_{j} \sim g\left(1, \tau \exp \left(\xi^{\prime} \mathbf{z}_{j}\right)\right)$. Behaviorally, this effect allows experience to cause respondents to become more similar/different with respect to how deterministic their choices are. ${ }^{18}$

This paper proposes a way in which experience can be accounted for in econometric modeling of consumers' preferences in a random utility framework as introduced above. In particular, by focusing on effects of experience on scale and scale variance, we implement a reduced form way for Bayesian updating to inform the econometric specification. In the remainder of the paper we demonstrate how this can influence preferences and public good willingness to pay estimates. ${ }^{19}$ The method developed in this paper is widely applicable to both stated and revealed preference data. ${ }^{20}$

There are a range of other lenses through which the effects of experience and learning on stated WTP have been investigated. The first relates to the literature on option values and the idea of commitment costs. Corrigan et al. (2008) use the framework of Zhao et al. (2004) to model the effects of being allowed to postpone a "purchase" decision over an environmental good in order to gain more information about it. WTP thus depends on expected gains in information in their framework. A second 
lens literature shows that experience can help people learn their preferences for unfamiliar goods within choice experiment settings, and that the context of this learning is very important (Plott, 1996; Bateman et al., 2008; Brown et al., 2008; Norwood et al., 2011). This works studies what helps preferences for unfamiliar goods or unfamiliar valuation mechanisms converge into stable values over repeated interactions which are consistent with the axioms of economic theory in what Brown et al. (2008) call "preference refinement". For example, convergence which exist for private goods through repeated transactions are almost never available for environmental public goods (Plott, 1996).

Finally, there are many papers which consider how people learn as they complete increasing numbers of choice tasks and the implications of this specifically for the scale parameter (see Czajkowski et al., 2014 for a recent review). In stated preferences, initial work by DeShazo et al. (2002) shows that the scale

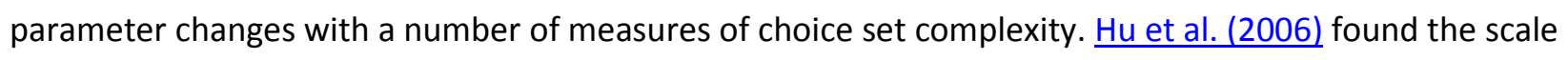
parameter decreases as respondents progress through choice sets and thus gain more experience in choosing. Finally, Lusk et al. (2008) finds that providing more information on choice options for consumer purchases has a significant effect on the scale parameter. Our paper is different from all of this previous work in that our goal is to develop an econometric framework to control for prior experience with a good (as opposed to an elicitation mechanism) in a theoretically consistent way, which as shown above has very specific implications for the scale parameter.

\subsection{Econometric treatment}

In this section we set out a method for accounting for the effects of experience on consumers' preferences in discrete choice models by allowing for experience-related observable and unobservable preference and scale heterogeneity in a manner consistent with the theoretical treatment of the 
preceding section. We later apply these methods using two case study data sets to investigate how experience and familiarity with the good influences respondents' preferences and scale.

The random utility framework presented in the previous section conveniently lends itself to econometric modeling - random utility theory is transformed into different econometric models by making assumptions about the distribution of the random error term and the random parameters. Typically, $\varepsilon_{i j}$ is assumed to be independently and identically (iid) Extreme Value Type 1 distributed across individuals and alternatives; in addition, assuming that all the random taste parameters are multivariate normally distributed $^{21}$ and that the individual scale parameter is log-normally distributed ${ }^{22}$ leads to the Generalized Multinomial Random Parameters Logit model type II (G-MNL; Fiebig et al., 2010). Following the notation introduced in section II, respondent $i$ 's utility associated with choosing alternative $j$ is:

$$
U_{i j t}=\left(\sigma_{i}\left(\mathbf{b}+\mathbf{u}_{i}\right)\right)^{\prime} \mathbf{x}_{i j t}+\varepsilon_{i j t}
$$

where the individual-specific random taste parameters are now represented by a vector of their population means $\mathbf{b}$ and individual-specific deviations from these means $\mathbf{v}_{i}$. The new subscript $t$ represents different choice tasks the same respondent may face - in discrete choice experiments an individual is confronted with a sequence of choice tasks which allows the researcher to extract more information from each respondent of the study, and facilitates identification of preference and scale heterogeneity (Ruud, 1996; Revelt et al., 1998; Fosgerau, 2006; Hess et al., 2011).

The key focus of our theoretical treatment is on the representation of the effects of experience in a random utility model. Therefore, we adapt the G-MNL model to account for the effects of experience, as explained in section II. This can be done by introducing indicators of experience or familiarity with the good (z) as covariates or means and variances of random taste parameters $\boldsymbol{\beta}_{\boldsymbol{j}} \sim \operatorname{MVN}\left(\mathbf{b}+\boldsymbol{\Phi}^{\prime} \mathbf{z}_{\boldsymbol{j}}, \boldsymbol{\Sigma} \exp \left(\boldsymbol{\Psi}^{\prime} \mathbf{z}_{\boldsymbol{j}}\right)\right)$ and/or as covariates of random scale and its variance $\sigma_{j} \sim \operatorname{LN}(1+$ 
$\left.\boldsymbol{\Phi}^{\prime} \boldsymbol{z}_{\boldsymbol{j}}, \tau+\boldsymbol{\xi}^{\prime} \mathbf{z}_{\boldsymbol{j}}\right) .{ }^{23}$ Importantly, allowing for scale heterogeneity provides a convenient way in which the behavior of the error term can be a function of previous experience which Section II shows must be allowed for in order for the empirical model to be consistent when allowing for Bayesian learning. Further, while the theoretical model predicts scale should increase in experience and scale variance should decrease with experience, thereby decreasing the magnitude of the error term relative to the deterministic portion of the utility, we do not restrict parameters estimates thereby permitting any relationship between experience and the parameters of interest. Finally, we do not have exogenous variation in experience. People who prefer the good more than others typically are observed as having a higher measured level of experience. Rather, our model tests and controls for learning through experience. $^{24}$ We cannot, therefore, make causal inference about the effect of experience on preferences.

The above model specification results in the following probability of observing respondent $i$ choosing alternative $j$ out of the $J$ available alternatives at choice occasion $t$ :

$$
\operatorname{Pr}\left(y_{i t}=j\right)=\frac{\exp \left(\exp \left(\sigma_{i}\left(\mathbf{b}+\boldsymbol{\phi}^{\prime} \mathbf{z}_{i}+\mathbf{u}_{i}\right)\right)^{\prime} \mathbf{x}_{i j t}\right)}{\sum_{k=1}^{j_{i t}} \exp \left(\left(\sigma_{i}\left(\mathbf{b}+\boldsymbol{\phi}^{\prime} \mathbf{z}_{i}+\mathbf{u}_{i}\right)\right)^{\prime} \mathbf{x}_{i k t}\right)}
$$

where:

$$
\begin{aligned}
& \sigma_{i}=\bar{\sigma}+\boldsymbol{\phi}^{\prime} \mathbf{z}_{i}+\tau \exp \left(\boldsymbol{\xi}^{\prime} \mathbf{z}_{i}\right) \varepsilon_{0 i} \\
& \mathbf{U}_{i}=\boldsymbol{\Gamma} \mathbf{\Omega} \boldsymbol{\zeta}_{i} \\
& \mathbf{\Omega}=\operatorname{diag}(\mathbf{s}) \exp \left(\boldsymbol{\Psi}^{\prime} \mathbf{z}_{i}\right)
\end{aligned}
$$

Since the probability is conditional on the random terms, the unconditional probability is obtained by multiple integration, the expression for which does not exist in closed form. Instead, it can be simulated by averaging over $D$ draws from the assumed distributions (Revelt et al., 1998). As a result, the simulated log-likelihood function becomes: 


$$
\log L=\sum_{i=i}^{l} \log \frac{1}{D} \sum_{d=1}^{D} \prod_{t=1}^{T_{i}} \frac{\exp \left(\left[\sigma_{i d}\left(\mathbf{b}+\boldsymbol{\phi}^{\prime} \mathbf{z}_{i}+\mathbf{U}_{i d}\right)\right]^{\prime} \mathbf{x}_{i j t}\right)}{\sum_{k=1}^{J_{i t}} \exp \left(\left[\sigma_{i d}\left(\mathbf{b}+\boldsymbol{\phi}^{\prime} \mathbf{z}_{i}+\mathbf{U}_{i d}\right)\right]^{\prime} \mathbf{x}_{i k t}\right)}
$$

In the Results section of this paper we estimate the above empirical model fora stated preference choice experiment. Because of the importance of information processing in motivating our approach, we are particularly interested in the coefficients on $\mathbf{z}$, which will be proxies for prior experience with the good being studied, and which enter the utility function as covariates of the scale parameter and its variance, thus allowing for Bayesian updating.

\section{Description of Data}

In this paper, we use a choice experiment data set to explore the effects of respondent experience with an environmental good, beach water quality, ideally suited to use the theoretical and econometric framework introduced above. Beach water quality is ideally suited for this exercise because the dataset contains a measure of previous experience with beach water quality (number of beach visits) allowing us to use our technique with a viable experience proxy. This section describes that data set.

This study considered the economic value of potential improvements to coastal water quality such as may result from implementation of changes to the European Union's Bathing Waters Directive in 2015 to people living in Northern Ireland. The focus of this Choice Experiment was on the valuation of changes in coastal water quality to those who use beaches in Northern Ireland for recreation. This group of respondents is likely to be particularly affected by changes planned under revisions to the Bathing Waters Directive, since many of the water quality parameters which this directive focuses on are those linked to human health and the exposure of beach users to illness from contact with water-borne pathogens. The current revisions to the Directive relate to greater restrictions upon the standards for 
bathing water. The attributes chosen for the DCE describe three relevant aspects of coastal water quality: benthic health, human health risks, and beach debris. For each aspect, respondents were able to select between no change to the existing policy, a small change and a large change. Supplementary online appendix B describes the three aspects in more detail. The per visit cost to an individual of visiting a beach with a given set characteristics (the costs of travel to the site) was used as the cost attribute. Travel costs have been used before as the price attribute in several choice experiments relating environmental quality changes to recreational behavior (e.g., Hanley et al., 2002; Christie et al., 2007). Six levels of additional cost were selected: $0, £ 0.6, £ 1.6, £ 3, £ 6$, and $£ 9$.

The design of the experiment was generated using efficient design principles. With three blocks, this meant that each individual responded to 8 choice cards. In each choice card, respondents were asked to choose the option they preferred from three choices. A sample choice card in included as Figure 2. Some 558 respondents were surveyed on-site at a range of beaches around the Northern Irish coast in autumn 2011.

In this study, the indicator of respondents' experience with the good "coastal water quality" which we used was the reported number of days spent at the beach each year (bdays). We are confident that number of days spent at the beach per year is a good proxy for experience here as beach quality is visually observable. It is also in the interest of beach goers to find out about water quality measures for health reasons before they enter the sea to go swimming or surfing, and such information is displayed on-site at designated beaches as part of a requirement of the Bathing Waters Directive.

The premise for using this dataset is that beach water quality is an experience good. Put another way, in order for the dataset to be valid in estimating our model, agents don't know their true "type", on average, for water quality until they have had experiences with it. The following chain of events must occur in order for the dataset to be valid in a study which appropriately controls for experience on WTP 
for public goods: 1) agents make a recreational choice conditional on their priors over their type, 2) while agents are engaged in recreational choice they experience the recreation environment, 3) one component of that environment is related to the relevant program (e.g., water quality along the beach), 4) agents update their preferences for said component of the environment (e.g., water quality). Importantly, the policy alternatives explicitly have the characteristic of affecting the "component of the environment" (e.g., water quality). This chain of events assures that we have measured valid experience proxies as well. In sum, then, since the policies relate environmental components for which agents have experienced via their recreational choices, they are able to update their preferences for those goods.

It should be noted that our measure of familiarity, number of visits to the beach, is not exogenous. It is likely to be correlated with preferences for amenities associated with each public good. Indeed, finding an instrument for experience or familiarity can always be an issue in empirical work on experience goods. As a result this study cannot identify a causal link between experience and scale nor scale variance. ${ }^{25}$ We can, however, still construct and estimate a model which is theoretically consistent with Bayesian updating of preferences and test whether the theoretical predictions of the model are consistent with the data.

\section{Results}

We estimated the augmented G-MNL model described in section 2.2 which allows us to account for the effects of experience on respondents' choices assuming that all taste parameters are random, normally distributed, and possibly correlated. The indicators of respondents' experience or familiarity with the good were included as covariates of scale and its variance. This section reports our results. We also briefly discuss important features of the policy covariates before discussing coefficient estimates for our experience proxies and their implications. 
The estimation was performed using Matlab 8.1 Optimization Toolbox, using 1000 shuffled Halton draws to simulate distributions of random parameters. We found the log-likelihood function of the G-MNL model to be relatively flat near the optimum - we therefore used multiple starting points and relatively tight convergence criteria to ensure convergence at the global maximum. ${ }^{26}$

Standard errors of coefficients associated with standard deviations of random parameters were simulated using Krinsky and Robb method with $10^{6}$ draws (Krinsky et al., 1986). We use the following dummy coded choice attributes: $S Q$ - an alternative specific constant associated with the no change (no improvements) alternative; improvements in benthic health $\left(B H_{1}-\right.$ small increase, $B H_{2}-$ large increase) with no improvement as a reference level; reductions of health risks ( $H R_{1}$ - reduction to $5 \%$ risk, $H R_{2}$ - reduction to 'very little risk') with the current $10 \%$ risk as a reference level; and improvements in debris management $\left(D M_{1}\right.$ - prevention, $D M_{2}-$ collection and prevention). In addition, the linearly coded variable FEE represented the additional cost of travelling to each beach. The resulting vector of choice-specific variables was:

$$
\mathbf{X}=S Q, B H_{1}, B H_{2}, H R_{1}, H R_{2}, D M_{1}, D M_{2}, F E E
$$

We used bday - log of the reported number of days spent at the beach each year (mean 74.89) as a proxy of respondents' experience or familiarity with coastal water quality. ${ }^{27}$

We estimate the model allowing the cost parameter to be random and non-random. Allowing a random cost parameter significantly outperforms the non-random cost parameter model by both the log likelihood criterion and the AIC, we provide the latter for comparison because it is a common practice in applied work aimed at calculating mean WTP (and not only its median). Table 1 presents our choice model estimates. The important distinction in it, though, is the comparison between allowing experience measures to enter the scale and scale variance measure (e.g., comparing column 1 to 2 and 
column 3 to 4) within each cost parameter specification. In each case, we assume the scale term is distributed log normally.

The taste parameters of the coastal water quality study are very well-behaved, all highly significant and of expected sign. There is a considerable amount of unobserved preference (taste) heterogeneity. The results indicate that respondents perceived improvements in debris management as the most important, followed by reductions in health risks and improvements in benthic health.

The number of days a respondent spent at the beach in the past year ( bday) was added as a covariate for scale and scale variance in columns 2 and 4 . Looking at the random cost results, respondents who visited beaches more often had a significantly higher scale parameter (i.e. lower magnitude of the error component in their random utility function) at the $1 \%$ level and significantly lower scale variance at the $10 \%$ level. This is consistent with the model of Bayesian updating developed in Section 2. Column four shows that when we restrict the cost parameter to be non-random, the effect of experience on mean scale is still positive and significant at the $10 \%$ level. The effect of experience on scale variance is still negative but is no longer significant at the $10 \%$.

Figure 3 plots mean scale and scale variance as a function of function of our experience proxy. The experience proxy is demeaned and normalized so that 0 corresponds to mean experience, and -1 and +1 to 1 standard deviation worth of deviations from the mean. Figure 3 shows that scale increases and scale variance decreases with experience. However, the estimates in the right-hand panel associated with the non-random cost parameter are much less precise. The rigidity of the non-random cost parameter trades off against the scale term since the scale term dictates the ability of the RUM to link each consumer to their stated preferences. In effect, then, allowing the cost parameter to be random permits the experience measure to have more explanatory power over the idiosyncratic error term. 
Taken together, Table 1 and Figure 3 provide support for the predictions of the theoretical model as applied to the econometric model presented in section 2. Evidence for the first prediction of the Bayesian model (experience increases mean scale) is more robust than for the second prediction (experience decreases scale variance).

Lastly, we perform a joint hypothesis test. We test whether as experience increases that both scale increases and scale heterogeneity decreases since the theoretical Bayesian model implies both occur the simultaneously. To do so, we perform a likelihood ratio test of the preferred model with random cost parameters in columns 1 and 2 and the models with non-random cost parameters in columns 3 and 4 . In the model with random cost (e.g., columns (1) versus (2)) the p-value for the joint test that increases in experience both increase scale and decrease scale heterogeneity is .0004 . In the model with random costs, then, adding experience related covariates significantly improves the model fit. The p-value in the model with non-random costs (e.g., columns (3) versus (4)) is .299. As a result, we fail to reject the null hypothesis that adding experience related covariates significantly improves model fit with non-random costs. As before, it appears that the rigidity of the non-random cost parameter trades off against the scale term since the scale term dictates the ability of the RUM to link each consumer to their stated preferences. For a public good for which agents have less preference heterogeneity, then, we would expect to reject the joint null hypothesis even in the model with non-random cost parameters. In sum, with the preferred random costs model we find evidence that agents update their preferences in a way consistent with Bayesian updating.

While we do not report results here, we also estimated the model while specifying a Weibull distribution for the scale parameter. The Weilbull distribution is advantageous in its shape flexibility, however, the variance of a Weibull distribution is a function of its scale and shape parameters, neither of which in and of itself fully determines the variance. In those regressions, evidence for the first prediction remained robust. For the second prediction, though, the estimated scale variance was not significant or even took 
to wrong sign. We therefore believe our results to provide strong evidence in our case study that the scale parameter increases with experience, however, evidence that scale variance across subjects decreases with experience is somewhat tenuous. Within a subject, then, scale increases with experience as predicted by the Bayesian model. However, across subjects, it appears that the implications of the Bayesian model are less well supported by this data. ${ }^{28}$

Although the main contribution of this paper is to investigate the effects of experience on preferences for an environmental public good in a theoretically consistent model, we also investigate the importance of controlling for experience on willingness to pay point estimates and confidence intervals. We calculated implicit prices associated with each attribute. Since the price coefficient in our studies was assumed random in the best fitting models, the ratio distribution resulting from dividing each random, normally distributed parameter associated with the attribute levels with the random, normally distributed cost coefficient does not have finite moments, i.e. no mean and standard deviation of the empirical (Cauchy-like) distribution of WTP exist ( WTP, along with its simulated standard error, and the 0.025 and 0.975 quantiles as proxies of the $95 \%$ confidence interval. In order to do so we adopted the following simulation method, based on the Krinsky and Robb parametric bootstrapping technique:

(1) we took $10^{5}$ multivariate normal draws from the estimated vector of model coefficients and the associated variance-covariance matrix;

(2) for each of the draws we assembled the variance-covariance matrix from the simulated elements of the lower triangular of Cholesky matrix and took $10^{5}$ multivariate normal draws using the simulated random taste parameters and their variance-covariance matrix;

(3) we calculated ratios of respective preference parameters to calculate WTP for each of the attribute levels. The empirical distributions of WTP allowed as to observe the median and the 
0.025 and 0.975 quantiles (95\% quantile range of WTP distribution) along with their simulated standard errors.

Table 2 compares the three different policy interventions for the water quality study. The median WTP estimates are very stable when experience is or is not included as a covariate for scale and scale variance. Both the magnitudes across econometric models and the WTP estimates within models are similar. Further, adding experience-related covariates to the water quality study does not significantly decrease the variance of median WTP estimates. It is important to stress, though, that these WTP estimates are for only one particular public good and there are several caveats to apply here. First, beach visits is only a proxy for peoples' experience with beach quality. It is possible that better measures exist. Second, the degree that consumers' priors are biased or unbiased for a good would affect how important including experience with a public good is. Third, since the second prediction of the Bayesian model is not as robust as the first, the particular theoretical model proposed here could need refinement. Indeed, these are fruitful areas for future research.

\section{Conclusions}

It is surprising that the full implications of experience on preferences have not received more attention in the literature on the estimation of demand for public goods for which market data does not exist. We offer a theoretical model which shows that within a Bayesian framework, not permitting scale and scale variance to vary with experience amounts to a mis-specification of the structure of the error term in random utility models. We then develop and estimate a reduced form econometric model of demand estimation which both extends the generalized multinomial logit model and is consistent with this Bayesian theoretical framework. 
The Bayesian theoretical predictions for the effects of more experience on the idiosyncratic component of utility are generally supported by data in our case study (coastal water quality). The results for the first theoretical prediction, that individuals with more experience have a higher estimated scale parameter, is strong and robust. The results for the second theoretical prediction, that heterogeneity in scale across respondents should decrease with experience, is present but less convincing motivating future work in this area. We show in supplementary online appendix A that the G-MNL model is also implementable with other theoretical approaches to learning.

There are several implications of the results in this paper. The first is whether consumers do update as Bayesians or use some other updating procedure. This paper shows that we cannot reject a Bayesian model of updating. However, this does not imply that the Bayesian model is the correct one since our results are not causal. Indeed, more work on the second theoretical prediction of the Bayesian model is needed. To that end, other models posited by the literature on the effects of experience on economic actions include behavioral models such as confirmatory bias and rational inattention (Rabin et al., 1999; Gabaix et al., 2006). Second, while we offer on theoretically consistent econometric model that controls for experience level, there are potentially other models yet to be implemented. Third, we can make no claims as to the causal effect of experience and learning on WTP. The causal effect of learning on WTP for public goods and policy options which change the supply of such goods is a question which requires further empirical work. Finally, we note that our model does not allow for the precise sequencing of experiences to matter for preferences or for scale, only their quantity. Further, we do not have any measure of the intensity of experiences in our data, only its frequency. It may also be that individuals sort heterogeneous experiences into a finite number of "categories", and that this process in itself helps determine the way in which experiences influence future choices (Fryer et al., 2008). All of these would be interesting sophistications to explore. 
${ }^{1}$ In addition, e.g., Brown et. al. (2008) and Kingsley et al. (2010) ask how agents value public goods as they have more experience in valuing them (rather than direct experience with the good being valued). For example, these papers have subjects repeatedly choose between binary states of the world within a given survey to see how preferences change and/or become more stable for a particular good within a given survey. These studies, then, ask important questions about the refinement of preferences which could come from thinking about a good, thinking about comparisons between management options for the good, or becoming more familiar with the survey or valuation technique within one particular survey. As a result, their preference uncertainty is quite different than our investigated here. More broadly, there is a larger body of work which addresses how familiarity with markets or valuation mechanisms can affect stated or revealed willingness to pay measures (List et al. 1998 and List 2001). In contrast our paper is about how previous experience with a particular public good affects WTP for it when elicited in a standard choice experiment. Combining these two approaches, we feel, is a fruitful area for future work.

${ }^{2}$ We do not address the much more complicated issue of the causal effect of learning on WTP. This paper merely seeks to control for extant effects of experience and learning in a theoretically consistent way.

${ }^{3}$ There is significant interest in empirically identifying how learning about private goods affects preference uncertainty and consumer demand (Erdem et al., 1996; Ackerberg, 2003; Crawford et al., 2005; Goeree, 2008;

Osborne, 2011). In this literature, a formal model of learning and information agglomeration is often integrated into the demand framework in a theoretically consistent way and estimation occurs in an explicitly Bayesian

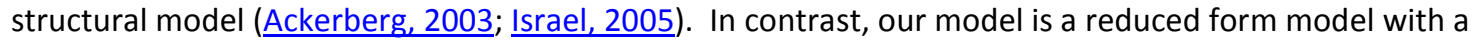
specification that is informed by theory.

${ }^{4}$ Insofar as our model decomposes the error in a choice experiment setting, this work builds on Scarpa et al. (2005).

${ }^{5}$ Whilst for the particular data sets and measures of experience used in this paper our "new approach" does not result in big differences in welfare measures, we think its merit lies in presenting a way to model the effects of experience in a manner which is theoretically consistent. 
${ }^{6}$ We relax this assumption below. Supplementary online appendix A considers the implications of more general utility specifications.

${ }^{7}$ Note that learning could affect both means and variances of random taste parameters, and as a result, the mean and variance of willingness to pay. This will be discussed in more detail below. Additionally, there is also a literature in marketing research which models the effects of past choices, expectations and learning-throughinspection on choices and preferences in the current period, which is very much in the spirit of the kind of Bayesian updating we employ here: see Meyer (1982), Meyer et al. (1997) and Meyer (2008).

${ }^{8}$ For example, when a new good is introduced, say a new restaurant, a consumer will not likely be able to distinguish between the possibility they like that restaurant more than the average patron (e.g., their $\delta_{i j}$ ) or if they happened to have a particularly good experience on that occasion (e.g., $\left.u_{i j t}\right)$.

${ }^{9}$ One could perform Monte Carlo simulations over the entire distribution not conditioning on realized signals. There would be no qualitative differences, though, as it would have the effect of increasing the size of the tails in each posterior distribution.

${ }^{10}$ Note that this result would hold even if the population error variance term were allowed to be heterogeneous across the population so long as it remains iid.

${ }^{11}$ In order to separately identify these two parameters, either a structural model or a panel dataset is needed. Given our focus on widely implementable WTP estimates for public and quasi-public goods (for which panel datasets are rare) we leave separately identifying these effects to future work.

${ }^{12}$ Note, that the scale cannot be econometrically separated from the other parameters of the utility function and the estimates of taste parameters are in fact multiplications of the underlying taste parameters and scale (Fiebig et al., 2010). With no loss of generality one can normalize scale to 1 and, due of the ordinal nature of various utility functions, treat the estimates of utility function taste parameters as true taste parameters, which can only be interpreted in relation to each other.

${ }^{13}$ For example, when one agent has very well-defined preferences, one would expect their deterministic component of utility to be large in magnitude relative to the idiosyncratic component.

${ }^{14}$ In this case the mean of the scale parameter is normalized to 1. 


\section{Experience and Preferences for Public Goods}

${ }^{15}$ We are grateful to an anonymous referee for pointing both of these things out to us.

${ }^{16}$ Thus, as Louviere and Meyer (2008) put it: “The estimated parameters of choice models reflect not just the enduring preferences that consumers may have for products and attributes, but also the momentary state of consumer learning about products." (page 22).

${ }^{17}$ Another way to interpret this is that the errors in the random utility model are heteroskedastic in previous experience.

${ }^{18}$ Another alternative, adding experience as an explanatory variable for parameter uncertainty (e.g., in the covariance matrix of a parameter in a random coefficient model), has no clear theoretical foundation either. The goal of this modelling approach is to build a widely implementable model that accounts for experience in a theoretically motivated way without having the endogeneity concerns of prior work (e.g., Carson et al., 2009). This model is flexible enough to control for learning through experience without being subject to the same endogeneity concern as using experience directly as a linear argument in the random utility function. Another alternative is allowing experience to directly affect preference parameters using a large structural model (Goeree, 2008; Osborne, 2011). While theoretically consistent, these labor intensive models are not easily implementable by researchers in a public and quasi-public good setting.

${ }^{19}$ There are other ways in which experience has been introduced in demand estimation studies and we briefly review them in ssupplementary online appendix A. This model, though, can be integrated with those alternative techniques as well - the technique we develop here is similar to those discussed in ssupplementary online appendix $\mathrm{A}$ if consumers, on average, have unbiased priors.

${ }^{20}$ Insofar as this model allows for scale heterogeneity across individuals, it builds on $\underline{\text { Train et al. (2005) }}$ and Scarpa et al. (2008), which could also potentially allow for adding similar experience related controls.

${ }^{21} \boldsymbol{\beta}_{j} \sim M V N(\mathbf{b}, \boldsymbol{\Sigma})$, so $\boldsymbol{\beta}_{i}=\mathbf{b}+\Gamma \Omega \boldsymbol{\varsigma}_{i}$, where $\Gamma \boldsymbol{\Omega}$ is a lower triangular matrix resulting from Cholesky decomposition of the variance-covariance matrix $\Sigma$ of random taste parameters $\Sigma=\Gamma \Omega(\Gamma \Omega)^{\prime}$ with the vector of square roots of diagonal elements $\mathbf{S}$ ), such that $\mathbf{\Gamma}$ has ones on the diagonal and possibly non-zero below diagonal elements accounting for correlations of random taste parameters, $\boldsymbol{\Omega}$ is a diagonal matrix of standard deviations $\mathbf{S}$, and $\boldsymbol{\zeta}_{i}$ 
is a vector of random, normally distributed unobserved taste variations associated with taste parameters (with mean vector 0 and covariance (identity) matrix I).

${ }^{22} \sigma_{j} \sim L N(1, \tau)$, so $\sigma_{i}=\exp \left(\bar{\sigma}+\tau \varepsilon_{0 i}\right)$ where $\varepsilon_{0 i} \sim N(0,1)$ and $\bar{\sigma}=-\tau^{2} / 2$.

${ }^{23}$ Since experience-related covariates enter diagonal elements of $\boldsymbol{\Sigma}$ only (i.e. only the variances of random taste parameters), $\mathbf{\Omega}=\operatorname{diag}(\mathbf{s}) \exp \left(\boldsymbol{\Psi}^{\prime} \mathbf{z}_{i}\right)$

${ }^{24}$ Put another way, if agents do update their preferences with additional consumption experiences then a G-MNL model which does not control for learning in a theoretically motivated way is misspecified.

${ }^{25}$ To do so, the econometrician would need a rich panel dataset for which there is not only an instrument but individuals' consumption patterns are tracked over time.

${ }^{26}$ In optimization we used the trust-region or the quasi-Newton algorithm (for cross-checking) with numerical gradient and $\mathrm{BHHH}$-type approximation of the Hessian. The convergence criteria for function change, maximum of the gradient, and the lower bound on the size of a step were set to $10^{-12}$, since we found that the levels and convergence criteria typically used in statistical packages (STATA, NLOGIT) terminated optimization prematurely, effectively making the results very sensitive to starting points. We believe this to be a result of a relatively flat $\mathrm{LL}$ function of the G-MNL model near its maximum and encourage other researchers who discovered problems with the G-MNL model convergence to try this approach.

${ }^{27}$ The variable was normalized so that its mean in the sample was 0 and its standard deviation 1. This allows us to investigate relative differences between experience between respondents without encountering numerical problems associated with very high values entering the scale parameter.

${ }^{28}$ While there is no clear theoretical reasons for doing so, consider the implications of adding experience related covariates to the right hand side of the random utility model. First, note that the econometrician cannot separately identify both effects on preferences and scale simultaneously. We do not report the results here although they are available upon request, but we re-estimated the model including experience related covariates on mean willingness to pay for various policies. They are insignificant in all cases but two policy options (SQ and FEE). Finally, likelihood ratio tests show that adding experience related covariates to means does not improve the fit of the models in any significant way. Taken together, this is evidence that the theoretical model foundations in 
Experience and Preferences for Public Goods

section two provide the structure to control for experience in a G-MNL model at least as well as adding experience related covariates to the right hand side of the random utility model. 
Experience and Preferences for Public Goods

\section{References}

Ackerberg, D. A., 2003. Advertising, learning, and consumer choice in experience good markets: an empirical examination. International Economic Review, 44(3):1007-1040.

Adamowicz, W. L., 1994. Habit Formation and Variety Seeking in a Discrete Choice Model of Recreation Demand. Journal of Agricultural and Resource Economics, 19(1):19-31.

Araña, J. E., León, C. J., and Quevedo, J. L., 2006. The effect of medical experience on the economic evaluation of health policies. A discrete choice experiment. Social Science and Medicine, 63(2):512-524.

Bateman, I. J., Burgess, D., Hutchinson, W. G., and Matthews, D. I., 2008. Learning design contingent valuation (LDCV): NOAA guidelines, preference learning and coherent arbitrariness. Journal of Environmental Economics and Management, 55(2):127-141.

Bateman, I. J., Carson, R. T., Day, B., Hanemann, M. W., Hanley, N., Hett, T., Jones-Lee, M., Loomes, G., Mourato, S., Özdemiroġlu, E., Pearce, D. W., Sudgen, R., and Swanson, J., 2004. Economic Valuation with Stated Preference Techniques: A Manual. Edward Elgar, Northampton, MA.

Boyle, K. J., Welsh, M. P., and Bishop, R. C., 1993. The Role of Question Order and Respondent Experience in Contingent-Valuation Studies. Journal of Environmental Economics and Management, 25(1):S80-S99.

Breffle, W. S., and Morey, E. R., 2000. Investigating Preference Heterogeneity In A Repeated DiscreteChoice Recreation Demand Model Of Atlantic Salmon Fishing. Marine Resource Economics, 15(1):1-20.

Brown, T. C., Kingsley, D., Peterson, G. L., Flores, N. E., Clarke, A., and Birjulin, A., 2008. Reliability of individual valuations of public and private goods: Choice consistency, response time, and preference refinement. Journal of Public Economics, 92(7):1595-1606. 
Experience and Preferences for Public Goods

Cameron, T. A., and Englin, J., 1997. Respondent Experience and Contingent Valuation of Environmental Goods. Journal of Environmental Economics and Management, 33(3):296-313.

Carson, R., and Louviere, J., 2011. A Common Nomenclature for Stated Preference Elicitation Approaches. Environmental and Resource Economics, 49(4):539-559.

Carson, R. T., and Czajkowski, M., 2014. The Discrete Choice Experiment Approach to Environmental Contingent Valuation. In: Handbook of choice modelling, S. Hess and A. Daly, eds., Edward Elgar, Northampton, MA.

Carson, R. T., Hanemann, W. M., and Wegge, T. C., 2009. A Nested Logit Model of Recreational Fishing Demand in Alaska. Marine Resource Economics, 24(2):101-129.

Christie, M., Hanley, N., and Hynes, S., 2007. Valuing enhancements to forest recreation using choice experiment and contingent behaviour methods. Journal of Forest Economics, 13(2-3):75-102.

Corrigan, J., Kling, C., and Zhao, J., 2008. Willingness to Pay and the Cost of Commitment: An Empirical Specification and Test. Environmental and Resource Economics, 40(2):285-298.

Crawford, G. S., and Shum, M., 2005. Uncertainty and Learning in Pharmaceutical Demand. Econometrica, 73(4):1137-1173.

Czajkowski, M., Giergiczny, M., and Greene, W. H., 2014. Learning and fatigue effects revisited. Investigating the effects of accounting for unobservable preference and scale heterogeneity. Land Economics, 90(2):323-350.

DeGroot, M. H., 1970. Optimal Statistical Decisions. John Wiley and Sons, Hoboken, NJ.

DeShazo, J. R., and Fermo, G., 2002. Designing Choice Sets for Stated Preference Methods: The Effects of Complexity on Choice Consistency. Journal of Environmental Economics and Management, 44(1):123-143.

Erdem, T., and Keane, M. P., 1996. Decision-Making Under Uncertainty: Capturing Dynamic Brand Choice Processes in Turbulent Consumer Goods Markets. Marketing Science, 15(1):1-20. 
Experience and Preferences for Public Goods

Ferrini, S., and Scarpa, R., 2007. Designs with a priori information for nonmarket valuation with choice experiments: A Monte Carlo study. Journal of Environmental Economics and Management, 53(3):342-363.

Fiebig, D. G., Keane, M. P., Louviere, J., and Wasi, N., 2010. The Generalized Multinomial Logit Model: Accounting for Scale and Coefficient Heterogeneity. Marketing Science, 29(3):393-421.

Fosgerau, M., 2006. Investigating the distribution of the value of travel time savings. Transportation Research Part B: Methodological, 40(8):688-707.

Fryer, R., and Jackson, M. O., 2008. A Categorical Model of Cognition and Biased Decision Making. The B.E. Journal of Theoretical Economics, 8(1).

Gabaix, X., Laibson, D., Moloche, G., and Weinberg, S., 2006. Costly Information Acquisition: Experimental Analysis of a Boundedly Rational Model. The American Economic Review, 96(4):1043-1068.

Goeree, M. S., 2008. Limited Information and Advertising in the U.S. Personal Computer Industry. Econometrica, 76(5):1017-1074.

Hanemann, W. M., 1984. Welfare Evaluations in Contingent Valuation Experiments with Discrete Responses. American Journal of of Agricultural Economics, 66(3):332-341.

Hanley, N., Kriström, B., and Shogren, J. F., 2009. Coherent Arbitrariness: On Value Uncertainty for Environmental Goods. Land Economics, 85(1):41-50.

Hanley, N., Wright, R. E., and Koop, G., 2002. Modelling Recreation Demand Using Choice Experiments: Climbing in Scotland. Environmental and Resource Economics, 22(3):449-466.

Hess, S., and Rose, J. M., 2012. Can scale and coefficient heterogeneity be separated in random coefficients models? Transportation, 39(6):1225-1239.

Hess, S., and Train, K., 2011. Recovery of inter- and intra-personal heterogeneity using mixed logit models. Transportation Research Part B: Methodological, 45(7):973-990. 
Experience and Preferences for Public Goods

Hinkley, D. V., 1969. On the ratio of two correlated normal random variables. Biometrika, 56(3):635-639.

Hu, W., Adamowicz, W. L., and Veeman, M. M., 2006. Labeling Context and Reference Point Effects in Models of Food Attribute Demand. American Journal of Agricultural Economics, 88(4):10341049.

Hynes, S., Tinch, D., and Hanley, N., 2013. Valuing improvements to coastal waters using choice experiments: An application to revisions of the EU Bathing Waters Directive. Marine Policy, 40(0):137-144.

Israel, M., 2005. Services as Experience Goods: An Empirical Examination of Consumer Learning in Automobile Insurance. The American Economic Review, 95(5):1444-1463.

Krinsky, I., and Robb, A. L., 1986. On approximating the statistical properties of elasticities. The Review of Economics and Statistics, 68(4):715-719.

Lancaster, K., 1966. A New Approach to Consumer Theory. Journal of Political Economy, 74(2):132-157.

List, J. A., 2001. Do Explicit Warnings Eliminate the Hypothetical Bias in Elicitation Procedures? Evidence from Field Auctions for Sportscards. The American Economic Review, 91(5):1498-1507.

List, J. A., and Shogren, J. F., 1998. Calibration of the difference between actual and hypothetical valuations in a field experiment. Journal of Economic Behavior \& Organization, 37(2):193-205.

Lusk, J. L., Fields, D., and Prevatt, W., 2008. An Incentive Compatible Conjoint Ranking Mechanism. American Journal of Agricultural Economics, 90(2):487-498.

Manski, C. F., 1977. The structure of random utility models. Theory and Decision, 8(3):229-254.

McFadden, D., 1974. Conditional Logit Analysis of Qualititative Choice Behaviour. In: Frontiers in Econometrics, P. Zarembka, ed., Academic Press, New York, NY, 105-142.

McFadden, D., 1976. The Revealed Preferences of a Government Bureaucracy: Empirical Evidence. The Bell Journal of Economics, 7(1):55-72. 
Experience and Preferences for Public Goods

Meyer, R., Erdem, T., Feinberg, F., Gilboa, I., Hutchinson, W., Krishna, A., Lippman, S., Mela, C., Pazgal, A., Prelec, D., and Joelx1nm, S. n., 1997. Dynamic Influences on Individual Choice Behavior. Marketing Letters, 8(3):349-360.

Meyer, R. J., 1982. A Descriptive Model of Consumer Information Search Behavior. Marketing Science, $1(1): 93-121$.

Meyer, R. J., 2008. Formal Choice Models of Informal Choices: What Choice Modeling Research Can, and Can't, Learn from Behavioral Theory. In: Review of Marketing Research, N. K. Malhotra, ed., Emerald Group, 3-32.

Monroe, K. B., 1976. The Influence of Price Differences and Brand Familiarity on Brand Preferences. Journal of Consumer Research, 3(1):42-49.

Nelson, P., 1970. Information and Consumer Behavior. Journal of Political Economy, 78(2):311-329.

Nelson, P., 1974. Advertising as Information. Journal of Political Economy, 82(4):729-754.

Norwood, F. B., and Lusk, J. L., 2011. A calibrated auction-conjoint valuation method: Valuing pork and eggs produced under differing animal welfare conditions. Journal of Environmental Economics and Management, 62(1):80-94.

Osborne, M., 2011. Consumer learning, switching costs, and heterogeneity: A structural examination. Quantitative Marketing and Economics, 9(1):25-70.

Plott, C. R., 1996. Rational Individual Behavior in Markets and Social Choice Processes: the Discovered Preference Hypothesis. In: The Rational Foundations of Economic Behaviour, K. Arrow, E. Colombatto, M. Perlaman, and C. Schmidt, eds., McMillian, London, 225-250.

Rabin, M., and Schrag, J. L., 1999. First Impressions Matter: A Model of Confirmatory Bias. The Quarterly Journal of Economics, 114(1):37-82.

Revelt, D., and Train, K., 1998. Mixed Logit with Repeated Choices: Households' Choices of Appliance Efficiency Level. Review of Economics and Statistics, 80(4):647-657. 
Ruud, P. A., 1996. Approximation and Simulation of the Multinomial Probit Model: An Analysis of Covariance Matrix Estimation. working paper, Department of Economics, University of California, Berkeley.

Scarpa, R., Ferrini, S., and Willis, K., 2005. Performance of Error Component Models for Status-Quo Effects in Choice Experiments. In: Applications of Simulation Methods in Environmental and Resource Economics, R. Scarpa and A. Alberini, eds., Springer Netherlands, 247-273.

Scarpa, R., Thiene, M., and Train, K., 2008. Utility in Willingness to Pay Space: A Tool to Address Confounding Random Scale Effects in Destination Choice to the Alps. American Journal of Agricultural Economics, 90(4):994-1010.

Stigler, G. J., and Becker, G. S., 1977. De Gustibus Non Est Disputandum. The American Economic Review, $67(2): 76-90$.

Train, K. E., and Weeks, M., 2005. Discrete Choice Models in Preference Space and Willingness-to-pay Space. In: Applications of Simulation Methods in Environmental and Resource Economics, R. Scarpa and A. Alberini, eds., Springer, Dordrecht, 1-16.

Whitehead, J. C., Blomquist, G. C., Hoban, T. J., and Clifford, W. B., 1995. Assessing the Validity and Reliability of Contingent Values: A Comparison of On-Site Users, Off-Site Users, and Non-users. Journal of Environmental Economics and Management, 29(2):238-251.

Zhao, J., and Kling, C. L., 2004. Willingness to Pay, Compensating Variation, and the Cost of Commitment. Economic Inquiry, 42(3):503-517. 
Figure 1. Updating of Beliefs of $\delta_{i j}^{k} \cdot \sigma_{o}^{2}, \sigma_{\delta}^{2}=1, \delta_{i j}^{0}=0, \delta_{i j}^{1}=\delta_{i j}^{2}=-.5$

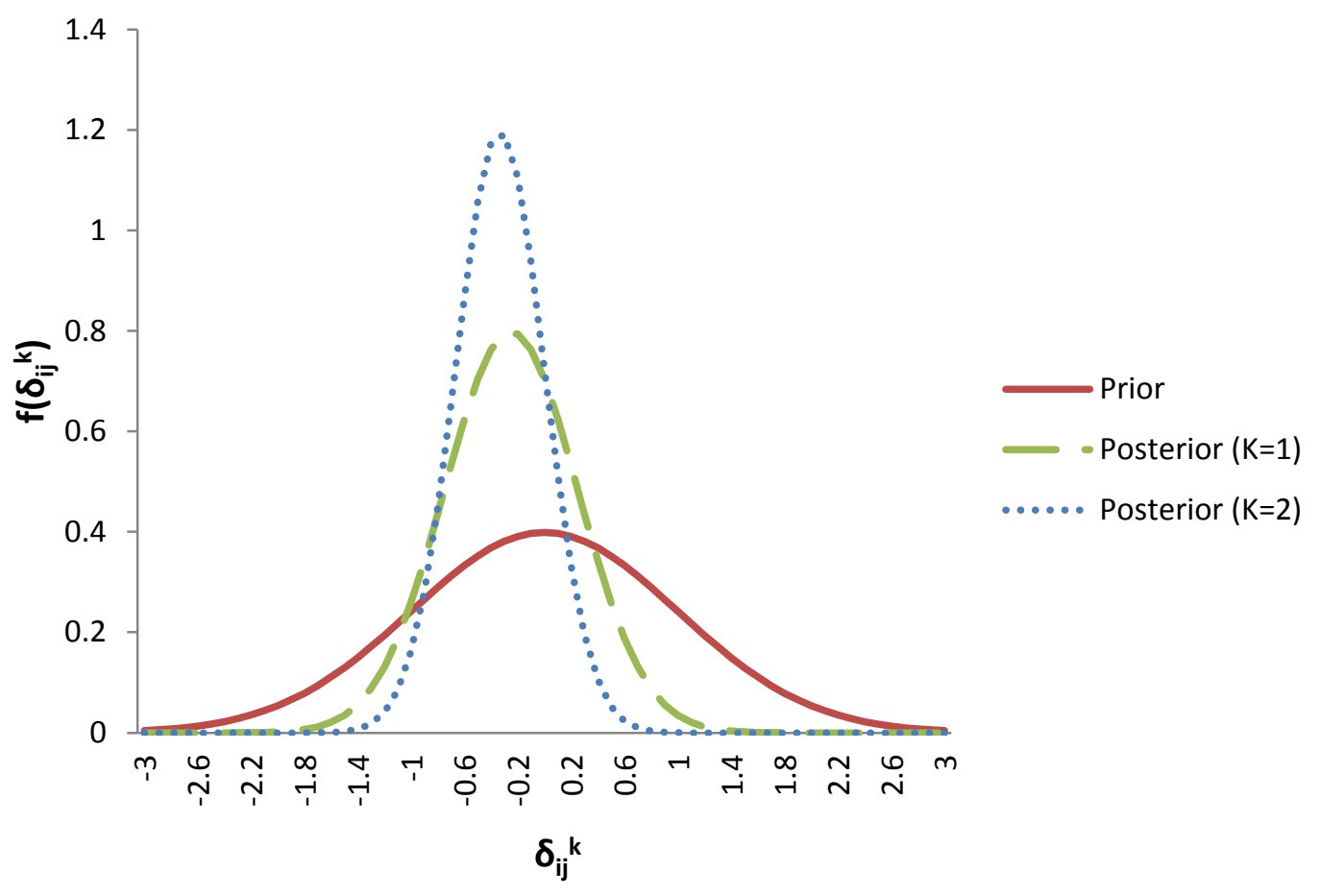


Figure 2. Example choice card from coastal water quality survey

\begin{tabular}{|c|c|c|c|}
\hline & Beach A & Beach B & Beach C \\
\hline $\begin{array}{l}\text { Benthic Health and } \\
\text { population. }\end{array}$ & $\begin{array}{c}\text { Small increase } \\
\text { More fish, mammals and } \\
\text { birds. Limited potential to } \\
\text { notice the change in species } \\
\text { numbers. }\end{array}$ & $\begin{array}{c}\text { Large increase } \\
\text { More fish, mammals and } \\
\text { birds and an increased } \\
\text { potential of seeing these } \\
\text { species. }\end{array}$ & No Improvement \\
\hline $\begin{array}{l}\text { Health Risk } \\
\text { (of stomach upsets and ear } \\
\text { infections) }\end{array}$ & $\begin{array}{c}\text { Very Little Risk } \\
\text { - excellent water quality }\end{array}$ & $\begin{array}{c}\mathbf{5 \%} \text { Risk } \\
\text { - good water quality }\end{array}$ & $\begin{array}{c}10 \% \text { Risk } \\
\text { - no improvement }\end{array}$ \\
\hline Debris Management & $\begin{array}{c}\text { Prevention } \\
\text { - more filtration of storm } \\
\text { water, more regular } \\
\text { cleaning of filters and better } \\
\text { policing of fly tipping. }\end{array}$ & $\begin{array}{c}\text { Collection and } \\
\text { Prevention } \\
\text { - debris collected from } \\
\text { beaches more regularly in } \\
\text { addition to filtration and } \\
\text { policing. }\end{array}$ & No Improvement \\
\hline $\begin{array}{l}\text { Additional cost of } \\
\text { travelling to each beach. }\end{array}$ & f3 & f9 & $£ 0$ \\
\hline $\begin{array}{l}\text { Please tick the ONE option } \\
\text { you prefer. }\end{array}$ & $\square$ & $\square$ & $\square$ \\
\hline
\end{tabular}


Figure 3. Scale dynamics associated with changes in respondent's experience indicator - coastal water quality study

\section{Cost parameter random}

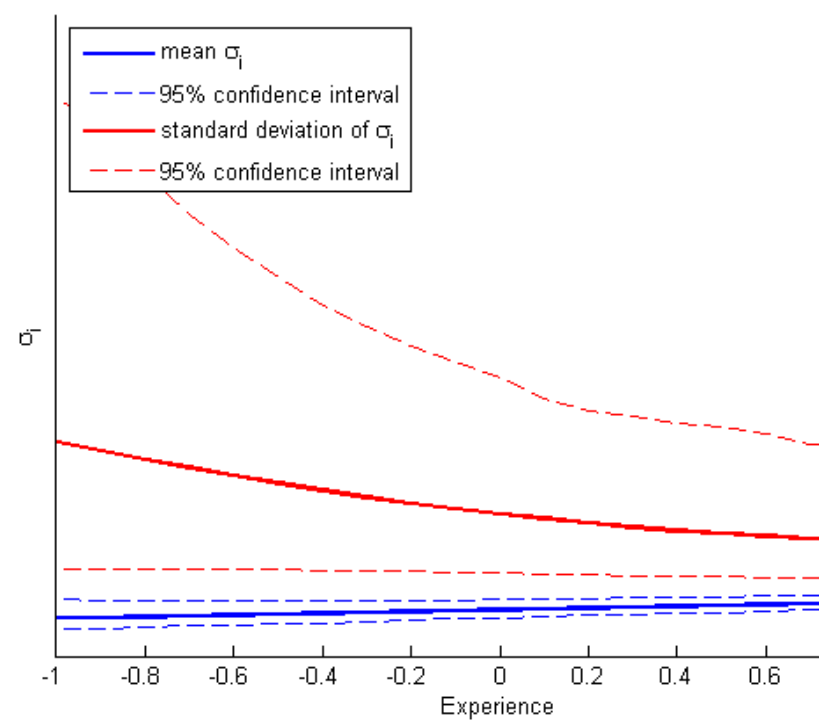

\section{Cost parameter non-random}

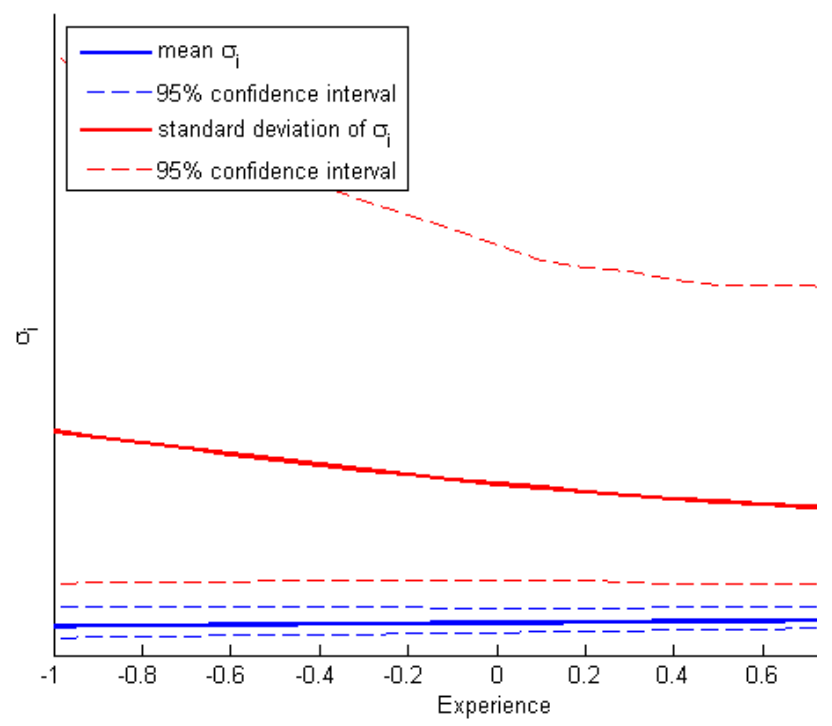


Experience and Preferences for Public Goods

Table 1. The discrete choice model results for the water quality study

\begin{tabular}{|c|c|c|c|c|}
\hline & $\begin{array}{c}\text { Model without } \\
\text { experience related } \\
\text { covariates }\end{array}$ & $\begin{array}{c}\text { Model with } \\
\text { experience related } \\
\text { covariates }\end{array}$ & $\begin{array}{c}\text { Model without } \\
\text { experience related } \\
\text { covariates }\end{array}$ & $\begin{array}{c}\text { Model with } \\
\text { experience related } \\
\text { covariates }\end{array}$ \\
\hline & \multicolumn{2}{|c|}{ Cost parameter random } & \multicolumn{2}{|c|}{ Cost parameter non-random } \\
\hline Variable & \multicolumn{4}{|c|}{$\begin{array}{l}\text { Coefficient of random parameter's mean } \\
\text { (s.e.) }\end{array}$} \\
\hline$S Q$ & $\begin{array}{c}-6.2235^{* * *} \\
(0.9624)\end{array}$ & $\begin{array}{c}-6.9032^{* * *} \\
(1.0761)\end{array}$ & $\begin{array}{c}-4.3221^{* * *} \\
(0.7027)\end{array}$ & $\begin{array}{c}-4.8224 * * * \\
(0.7773)\end{array}$ \\
\hline$B H_{1}$ & $\begin{array}{c}0.9663^{* * *} \\
(0.1849)\end{array}$ & $\begin{array}{c}1.0974 * * * \\
(0.2097)\end{array}$ & $\begin{array}{c}0.9288^{* * *} \\
(0.1486)\end{array}$ & $\begin{array}{c}0.9326 * * * \\
(0.1555)\end{array}$ \\
\hline $\mathrm{BH}_{2}$ & $\begin{array}{c}1.1917^{* * *} \\
(0.253)\end{array}$ & $\begin{array}{c}1.2973 * * * \\
(0.2896)\end{array}$ & $\begin{array}{c}1.5507^{* * *} \\
(0.2902)\end{array}$ & $\begin{array}{c}1.4806 * * * \\
(0.264)\end{array}$ \\
\hline$H R_{1}$ & $\begin{array}{c}1.0595^{* * *} \\
(0.2185)\end{array}$ & $\begin{array}{c}1.1472 * * * \\
(0.2458)\end{array}$ & $\begin{array}{c}1.1089 * * * \\
(0.1646)\end{array}$ & $\begin{array}{c}1.0991 * * * \\
(0.1702)\end{array}$ \\
\hline$H R_{2}$ & $\begin{array}{c}1.4573 * * * \\
(0.2696)\end{array}$ & $\begin{array}{l}1.63^{* * *} \\
(0.3164)\end{array}$ & $\begin{array}{c}1.7139 * * * \\
(0.2131)\end{array}$ & $\begin{array}{c}1.7347^{* * *} \\
(0.2255)\end{array}$ \\
\hline$D M_{1}$ & $\begin{array}{c}1.7213^{* * *} \\
(0.2445)\end{array}$ & $\begin{array}{c}1.8525^{* * *} \\
(0.2706)\end{array}$ & $\begin{array}{c}1.3682 * * * \\
(0.1811)\end{array}$ & $\begin{array}{c}1.4081^{* * *} \\
(0.1887)\end{array}$ \\
\hline$D M_{2}$ & $\begin{array}{c}1.9632^{* * *} \\
(0.2182)\end{array}$ & $\begin{array}{c}2.1083^{* * *} \\
(0.246)\end{array}$ & $\begin{array}{c}1.5012^{* * *} \\
(0.1699)\end{array}$ & $\begin{array}{c}1.5612^{* * *} \\
(0.177)\end{array}$ \\
\hline \multirow[t]{2}{*}{ FEE } & $\begin{array}{c}-0.6096 * * * \\
(0.0606)\end{array}$ & $\begin{array}{c}-0.6513^{* * *} \\
(0.0713)\end{array}$ & $\begin{array}{c}-0.3253^{* * *} \\
(0.0237)\end{array}$ & $\begin{array}{c}-0.3296 * * * \\
(0.0257)\end{array}$ \\
\hline & \multicolumn{4}{|c|}{$\begin{array}{l}\text { Coefficient of random parameter's standard deviation } \\
\text { (s.e.) }\end{array}$} \\
\hline$S Q$ & $\begin{array}{c}9.0032 * * * \\
(1.1993)\end{array}$ & $\begin{array}{c}9.5732 * * * \\
(1.3662)\end{array}$ & $\begin{array}{c}.6334^{* * *} \\
(0.9958)\end{array}$ & $\begin{array}{c}8.3312 * * * \\
(1.1128)\end{array}$ \\
\hline$B H_{1}$ & $\begin{array}{c}1.0613 * * * \\
(0.2338)\end{array}$ & $\begin{array}{c}1.2119 * * * \\
(0.2487)\end{array}$ & $\begin{array}{c}1.0075^{* * *} \\
(0.1638)\end{array}$ & $\begin{array}{l}0.981 * * * \\
(0.1731)\end{array}$ \\
\hline $\mathrm{BH}_{2}$ & $\begin{array}{c}2.2316^{* * *} \\
(0.3639)\end{array}$ & $\begin{array}{c}2.4352 * * * \\
(0.4044)\end{array}$ & $\begin{array}{c}2.9763 * * * \\
(0.3362)\end{array}$ & $\begin{array}{c}2.5499 * * * \\
(0.3222)\end{array}$ \\
\hline$H R_{1}$ & $\begin{array}{c}1.3446 * * * \\
(0.2871)\end{array}$ & $\begin{array}{c}1.5015^{* * *} \\
(0.317)\end{array}$ & $\begin{array}{c}0.9741 * * * \\
(0.2583)\end{array}$ & $\begin{array}{c}0.8996 * * * \\
(0.2926)\end{array}$ \\
\hline$H R_{2}$ & $\begin{array}{c}1.8176 * * * \\
(0.3322)\end{array}$ & $\begin{array}{l}1.977^{* * *} \\
(0.3692)\end{array}$ & $\begin{array}{c}1.4608 * * * \\
(0.302)\end{array}$ & $\begin{array}{c}1.4794 * * * \\
(0.3464)\end{array}$ \\
\hline$D M_{1}$ & $\begin{array}{c}2.014^{* * *} \\
(0.3052)\end{array}$ & $\begin{array}{c}2.0671 * * * \\
(0.341)\end{array}$ & $\begin{array}{c}1.7239 * * * \\
(0.3723)\end{array}$ & $\begin{array}{c}1.8737 * * * \\
(0.4237)\end{array}$ \\
\hline$D M_{2}$ & $\begin{array}{c}1.554 * * * \\
(0.3349)\end{array}$ & $\begin{array}{c}1.5536 * * * \\
(0.3409)\end{array}$ & $\begin{array}{c}1.6179 * * * \\
(0.3427)\end{array}$ & $\begin{array}{c}1.7868 * * * \\
(0.3837)\end{array}$ \\
\hline FEE & $\begin{array}{c}0.6839 * * * \\
(0.0649)\end{array}$ & $\begin{array}{c}0.7411 * * * \\
(0.0766)\end{array}$ & $\begin{array}{c}0 \\
\text { (fixed parameter) }\end{array}$ & $\begin{array}{c}0 \\
\text { (fixed parameter) }\end{array}$ \\
\hline & \multicolumn{4}{|c|}{$\begin{array}{c}\text { Coefficient of scale-related parameter } \\
\text { (s.e.) }\end{array}$} \\
\hline
\end{tabular}


Experience and Preferences for Public Goods

\begin{tabular}{|c|c|c|c|c|}
\hline $\begin{array}{l}\text { Scale variance } \\
\text { parameter }(\tau)\end{array}$ & $\begin{array}{c}2.4894 * * * \\
(0.2503)\end{array}$ & $\begin{array}{c}1.6378 * * * \\
(0.5311)\end{array}$ & $\begin{array}{c}2.6779 * * * \\
(0.2591)\end{array}$ & $\begin{array}{c}2.1337 * * * \\
(0.7018)\end{array}$ \\
\hline $\begin{array}{c}\text { Covariates of scale } \\
\text { (bday) }\end{array}$ & $\begin{array}{c}0 \\
\text { (fixed parameter) }\end{array}$ & $\begin{array}{c}0.1971 * * * \\
(0.0753)\end{array}$ & $\begin{array}{c}0 \\
\text { (fixed parameter) }\end{array}$ & $\begin{array}{l}0.1077^{*} \\
(0.0608)\end{array}$ \\
\hline \multirow[t]{2}{*}{$\begin{array}{l}\text { Covariates of scale } \\
\text { variance (bday) }\end{array}$} & $\begin{array}{c}0 \\
\text { (fixed parameter) }\end{array}$ & $\begin{array}{c}-0.2785^{*} \\
(0.1423)\end{array}$ & $\begin{array}{c}0 \\
\text { (fixed parameter) }\end{array}$ & $\begin{array}{l}-0.1862 \\
(0.1415)\end{array}$ \\
\hline & \multicolumn{4}{|c|}{ Model characteristics } \\
\hline $\begin{array}{l}\text { Log-likelihood } \\
\text { (constants only) }\end{array}$ & -4691.6270 & -4691.6270 & -4691.6270 & -4691.6270 \\
\hline Log-likelihood & -2684.9963 & -2677.2128 & -2928.4668 & -2927.2602 \\
\hline $\begin{array}{l}\text { McFadden's } \\
\text { pseudo } \mathrm{R}^{2}\end{array}$ & 0.4277 & 0.4294 & 0.3758 & 0.37607 \\
\hline $\mathrm{AIC} / n$ & 1.2508 & 1.2482 & 1.3581 & 1.3585 \\
\hline$n$ (observations) & 4366 & 4366 & 4366 & 4366 \\
\hline$k$ (parameters) & 45 & 47 & 36 & 38 \\
\hline
\end{tabular}

Note: $*, * *$, and $* * *$ for $10 \%, 5 \%$ and $1 \%$ significance levels, respectively. 
Table 2. Implicit prices for the water quality study

\begin{tabular}{|c|c|c|c|c|c|c|c|c|}
\hline & \multicolumn{2}{|c|}{$\begin{array}{l}\text { Model without experience } \\
\text { related covariates }\end{array}$} & \multicolumn{2}{|c|}{$\begin{array}{l}\text { Model with experience } \\
\text { related covariates }\end{array}$} & \multicolumn{2}{|c|}{$\begin{array}{l}\text { Model without experience } \\
\text { related covariates }\end{array}$} & \multicolumn{2}{|c|}{$\begin{array}{l}\text { Model with experience related } \\
\text { covariates }\end{array}$} \\
\hline & \multicolumn{4}{|c|}{ Cost parameter random } & \multicolumn{4}{|c|}{ Cost parameter non-random } \\
\hline & $\begin{array}{c}\text { median } \\
\text { (s.e.) }\end{array}$ & $\begin{array}{l}95 \% \text { quantile } \\
\text { range }\end{array}$ & $\begin{array}{c}\text { median } \\
\text { (s.e.) }\end{array}$ & $\begin{array}{c}95 \% \text { quantile } \\
\text { range }\end{array}$ & $\begin{array}{c}\text { median/mean } \\
\text { (s.e.) }\end{array}$ & $\begin{array}{c}95 \% \text { quantile } \\
\text { range }\end{array}$ & $\begin{array}{l}\text { median/mean } \\
\text { (s.e.) }\end{array}$ & $\begin{array}{c}95 \% \text { quantile } \\
\text { range }\end{array}$ \\
\hline$S Q$ & $\begin{array}{l}-2.72 * * * \\
(0.7903)\end{array}$ & $-4.3--1.19$ & $\begin{array}{l}-2.84^{* * *} \\
(0.8109)\end{array}$ & $-4.47--1.24$ & $\begin{array}{c}-13.31 * * * \\
(1.7184)\end{array}$ & $-16.54--9.86$ & $\begin{array}{c}-14.63^{* * *} \\
(1.8605)\end{array}$ & $-18.12--10.76$ \\
\hline$B H_{1}$ & $\begin{array}{l}0.99 * * * \\
(0.2605)\end{array}$ & $0.49-1.52$ & $\begin{array}{l}1.06 * * * \\
(0.2676)\end{array}$ & $0.55-1.61$ & $\begin{array}{l}2.86 * * * \\
(0.4316)\end{array}$ & $1.99-3.71$ & $\begin{array}{l}2.83^{* * *} \\
(0.4211)\end{array}$ & $2-3.65$ \\
\hline $\mathrm{BH}_{2}$ & $\begin{array}{c}0.81^{* *} \\
(0.3506)\end{array}$ & $0.15-1.54$ & $\begin{array}{c}0.78 * * \\
(0.3677)\end{array}$ & $0.09-1.56$ & $\begin{array}{l}4.75^{* * *} \\
(0.7959)\end{array}$ & $3.16-6.29$ & $\begin{array}{l}4.51 * * * \\
(0.6671)\end{array}$ & $3.16-5.74$ \\
\hline$H R_{1}$ & $\begin{array}{l}0.66 * * \\
(0.335)\end{array}$ & $0.03-1.34$ & $\begin{array}{c}0.64 * \\
(0.3559)\end{array}$ & $-0.03-1.37$ & $\begin{array}{c}3.4^{* * *} \\
(0.4803)\end{array}$ & $2.47-4.36$ & $\begin{array}{l}3.33 * * * \\
(0.4954)\end{array}$ & $2.39-4.33$ \\
\hline$H R_{2}$ & $\begin{array}{c}0.87 * * \\
(0.4195)\end{array}$ & $0.09-1.73$ & $\begin{array}{c}0.92 * * \\
(0.4509)\end{array}$ & $0.07-1.82$ & $\begin{array}{l}5.26 * * * \\
(0.5804)\end{array}$ & $4.13-6.43$ & $\begin{array}{l}5.27^{* * * *} \\
(0.6082)\end{array}$ & $4.09-6.48$ \\
\hline$D M_{1}$ & $\begin{array}{l}1.21 * * * \\
(0.3534)\end{array}$ & $0.54-1.91$ & $\begin{array}{l}1.24 * * * \\
(0.3471)\end{array}$ & $0.58-1.94$ & $\begin{array}{l}4.21 * * * \\
(0.4799)\end{array}$ & $3.28-5.15$ & $\begin{array}{l}4.28 * * * \\
(0.4845)\end{array}$ & $3.33-5.22$ \\
\hline$D M_{2}$ & $\begin{array}{l}1.71^{* * *} \\
(0.2688)\end{array}$ & $1.18-2.23$ & $\begin{array}{l}1.68^{* * *} \\
(0.2649)\end{array}$ & $1.15-2.19$ & $\begin{array}{l}4.61^{* * *} \\
(0.4308)\end{array}$ & $3.79-5.49$ & $\begin{array}{l}4.73 * * * \\
(0.4372)\end{array}$ & $3.9-5.61$ \\
\hline
\end{tabular}

Note: ${ }^{*}, * *$ and ${ }^{* * *}$ for $10 \%, 5 \%$ and $1 \%$ significance levels, respectively. 